\title{
Lipid Rafts Mediate the Synaptic Localization of $\alpha$-Synuclein
}

\author{
Doris L. Fortin, Matthew D. Troyer, Ken Nakamura, Shin-ichiro Kubo, Malcolm D. Anthony, and Robert H. Edwards \\ Departments of Neurology and Physiology, Graduate Programs in Biomedical Sciences, Cell Biology and Neuroscience, University of California San \\ Francisco School of Medicine, San Francisco, California 94143-2140
}

$\alpha$-Synuclein contributes to the pathogenesis of Parkinson's disease (PD), but its precise role in the disorder and its normal function remain poorly understood. Consistent with a presumed role in neurotransmitter release and its prominent deposition in the dystrophic neurites of PD, $\alpha$-synuclein localizes almost exclusively to the nerve terminal. In brain extracts, however, $\alpha$-synuclein behaves as a soluble, monomeric protein. Using a binding assay to characterize the association of $\alpha$-synuclein with cell membranes, we find that $\alpha$-synuclein binds saturably and with high affinity to characteristic intracellular structures that double label for components of lipid rafts. Biochemical analysis demonstrates the interaction of $\alpha$-synuclein with detergent-resistant membranes and reveals a shift in electrophoretic mobility of the raft-associated protein. In addition, the A30P mutation associated with PD disrupts the interaction of $\alpha$-synuclein with lipid rafts. Furthermore, we find that both the A30P mutation and raft disruption redistribute $\alpha$-synuclein away from synapses, indicating an important role for raft association in the normal function of $\alpha$-synuclein and its role in the pathogenesis of PD.

Key words: synuclein; Parkinson's disease; neurodegeneration; lipid raft; nerve terminal; synaptic localization

\section{Introduction}

Parkinson's disease (PD) involves the selective degeneration of dopamine neurons in the substantia nigra. Although the pathogenesis of PD remains poorly understood, converging evidence indicates a central role for the presynaptic protein $\alpha$-synuclein. Mutations in $\alpha$-synuclein cause a rare autosomal dominant form of PD (Polymeropoulos et al., 1997; Kruger et al., 1998; Zarranz et al., 2004). In addition, increased dosage of the wild-type gene appears sufficient to produce PD (Singleton et al., 2003). $\alpha$-Synuclein is also a major component of Lewy bodies, the cytoplasmic inclusions characteristic of PD (Spillantini et al., 1997, 1998), supporting its role in the idiopathic disorder. Furthermore, the dystrophic neurites of idiopathic PD contain abundant $\alpha$-synuclein (Galvin et al., 1999).

Despite an important role in PD, the mechanism by which $\alpha$-synuclein influences neural degeneration and indeed its normal function remain unclear. In vivo, $\alpha$-synuclein localizes almost exclusively to synaptic terminals (Maroteaux et al., 1988; Jakes et al., 1994; Iwai et al., 1995; Withers et al., 1997; Murphy et al., 2000). Consistent with this subcellular location, the expression of $\alpha$-synuclein has been found to correlate with changes in synaptic plasticity and has been suggested to influence certain features of neurotransmitter release (George et al., 1995; Abeliovich et al., 2000; Murphy et al., 2000; Cabin et al., 2002). Nonethe-

Received April 26, 2004; revised May 22, 2004; accepted June 10, 2004.

This work was supported by the University of California San Francisco Sandler (enter (R.H.E.), Valley Foundation (R.H.E.), National Institute of Neurological Disorders and Stroke (M.D.T.), and Hillblom Foundation (D.L.F.). We thank E. Fon for the $\alpha$-synuclein CDNAs; F. Brodsky, R. Kelly, S. Finkbeiner, and T. Ryan for helpful discussions; K. Mostov for use of the LI-COR Odyssey scanner; and A. Schmidt and L. R. Reichardt for assistance generating the transgenic mice.

Correspondence should be addressed to R. H. Edwards, Departments of Neurology and Physiology, University of California San Francisco, School of Medicine, 600 Sixteenth Street, San Francisco, CA 94143-2140. E-mail: edwards@itsa.ucsf.edu.

DOI:10.1523/JNEUROSCI.1594-04.2004

Copyright $\odot 2004$ Society for Neuroscience $\quad$ 0270-6474/04/246715-09\$15.00/0 less, $\alpha$-synuclein behaves as a soluble protein by differential centrifugation and gradient fractionation (Ueda et al., 1993; George et al., 1995; Iwai et al., 1995; Kahle et al., 2000). The mechanisms responsible for its synaptic localization are thus not preserved in standard biochemical studies.

In vitro, $\alpha$-synuclein binds to artificial membranes (Eliezer et al., 2001; Jo et al., 2002; Chandra et al., 2003), especially those containing acidic phospholipids (Davidson et al., 1998). $\alpha$-Synuclein has also been shown to associate as a peripheral membrane protein with synaptic vesicles (Maroteaux et al., 1988), axonal transport vesicles (Jensen et al., 1998), lipid droplets (Cole et al., 2002), and yeast membranes (Outeiro and Lindquist, 2003). However, the relationship of these observations to the synaptic localization of $\alpha$-synuclein in neurons and the changes that lead to PD remains unclear.

We now show that $\alpha$-synuclein associates specifically with lipid rafts. The A30P mutation linked to PD blocks the interaction with rafts, and raft association is required for the synaptic localization of $\alpha$-synuclein. The results thus suggest an important role for rafts in the normal function of $\alpha$-synuclein and raise the possibility that perturbing raft association may induce changes in $\alpha$-synuclein that contribute to the pathogenesis of PD.

\section{Materials and Methods}

Reagents. The rat monoclonal antibody (15G7) to human $\alpha$-synuclein was obtained from Alexis Biochemicals (San Diego, CA); the mouse monoclonal antibodies to CD55 (used for immunofluorescence), major histocompatibility complex (MHC) class I, phosphatidylinositol-4,5bisphosphate, thy-1, and transferrin receptor were from Oncogene Sciences (Uniondale, NY), Research Diagnostics (Flanders, NJ), Assay Designs (Ann Arbor, MI), BD Biosciences (San Diego, CA), and Zymed (San Francisco, CA), respectively; the CD55 antibody used for Western blotting and the antibody to focal adhesion kinase (FAK) were from Santa Cruz Biotechnology (Santa Cruz, CA); and the glutathione $S$-transferase (GST) antiserum was from Molecular Probes (Eugene, 
OR). Polyclonal anti-synaptophysin antibody was obtained from Zymed, and antibodies to $\alpha$-tubulin and caveolin-1 were from Oncogene and BD Biosciences. F. Brodsky (University of California San Francisco) generously provided a mouse monoclonal antibody to clathrin heavy chain, and R. B. Kelly (University of California San Francisco) provided the monoclonal antibody to SV2. Secondary antibodies conjugated to horseradish peroxidase were purchased from Amersham Biosciences (Arlington Heights, IL), and Cy2, Cy3, Cy5, and FITC-conjugated secondary antibodies were from Jackson ImmunoResearch (West Grove, PA). IR800-conjugated anti-rabbit antibody was obtained from LI-COR Biosciences (Lincoln, NE), cholera toxin subunit B conjugated to biotin was from Sigma (St. Louis, MO), and streptavidin-Alexa546 was from Molecular Probes. High purity digitonin, mevastatin, fumonisin $B_{1}$, and nystatin were purchased from Calbiochem (La Jolla, CA), and $\beta$-methylcyclodextrin and mevalonic acid were from Sigma.

Molecular biology and cell culture. $\alpha$-Synuclein cDNA was amplified by PCR from a human brain library, and PCR mutagenesis was used to introduce the A30P and A53T mutations. All constructs were verified by sequence analysis. To express recombinant protein in bacteria, $\alpha$-synuclein was subcloned into pGEX (Amersham Biosciences) and pCAL-n-FLAG (Stratagene, Cedar Creek, TX) vectors and transformed into Escherichia coli strain BL21. For expression in mammalian cell culture, wild-type and mutant $\alpha$-synuclein cDNAs were subcloned into pcDNA3 (Invitrogen, San Diego, CA), pEGFP-N1, and C2 (Clontech, Cambridge, UK). HeLa cells were grown in DMEM with $10 \%$ cosmic calf serum (HyClone, Logan, UT) at $5 \% \mathrm{CO}_{2}$ on either plastic or poly-Dlysine-coated glass coverslips (for immunofluorescence) and transfected using the Effectene reagent (Qiagen, Hilden, Germany). Recombinant adenoviruses directing the expression of GFP-tagged and untagged wildtype and mutant $\alpha$-synuclein were generated by CRE8-mediated recombination in human embryonic kidney 293 cells (Hardy et al., 1997). Dissociated hippocampal cultures containing glia were prepared from embryonic day 18.5 rats and maintained in neurobasal medium for 2-3 weeks (Higgins and Banker, 1998).

Synuclein binding in permeabilized cells. Two days after transfection with DNA or infection with recombinant adenovirus, HeLa cells expressing wild-type $\alpha$-synuclein, $\alpha$-synuclein-GFP, and the corresponding $\mathrm{A} 53 \mathrm{~T}$ and $\mathrm{A} 30 \mathrm{P}$ mutants were permeabilized for $5 \mathrm{~min}$ at room temperature in 12.5 mм HEPES-KOH, pH 7.4, 50 mм PIPES-KOH, pH 6.9, $1 \mathrm{~mm} \mathrm{MgSO}_{4}$, and $4 \mathrm{~mm}$ EGTA-KOH [cytoskeleton buffer (CB)] containing $40 \mu \mathrm{M}$ digitonin. After five washes in PBS, pH 7.4, including one for $5 \mathrm{~min}$, the cells were fixed in 4\% PFA and imaged directly in the case of GFP-tagged $\alpha$-synuclein, or immunostained in PBS containing 5\% cosmic calf serum (Hyclone) and $0.05 \%$ saponin. Alternatively, untransfected HeLa cells grown to $75 \%$ confluence were permeabilized in $\mathrm{CB}$ containing $40 \mu \mathrm{M}$ digitonin and recombinant, bacterially expressed GST$\alpha$-synuclein for $5 \mathrm{~min}$ at room temperature, washed as above in PBS, fixed, and immunostained for GST. Competition experiments involved incubation of the permeabilized HeLa cells in $200 \mathrm{~nm}$ GST- $\alpha$-synuclein and increasing amounts of calmodulin-binding protein (CBP)- $\alpha$ synuclein followed by immunofluorescence or quantitative Western blotting for GST. Fluorescence images were acquired on a Zeiss (Oberkochen, Germany) LSM 510 confocal laser-scanning microscope using a fixed laser strength, pinhole size, and detector gain for all samples within a single experiment.

Quantitative Western blotting. The competition assay was performed as described above with the exception that cells were permeabilized for 15 $\mathrm{min}$. At the end of the assay, cells were harvested in sample buffer, and the protein was separated by electrophoresis through Criterion Tris- $\mathrm{HCl}$ polyacrylamide gels (Bio-Rad, Hercules, CA), electrotransferred to polyvinylidene difluoride (PVDF) and immunostained with the appropriate antibodies. The immunoblots were scanned and protein was quantified using the Odyssey Infrared Imaging System (LI-COR Biosciences) and Odyssey analysis software.

Isolation of detergent-resistant membranes. Cells were harvested $2 \mathrm{~d}$ after transfection using a nonenzymatic cell dissociation buffer (Invitrogen), pelleted at $5000 \times g$, and detergent-resistant membranes were isolated as previously described (Field et al., 1995). Briefly, the HeLa cells were resuspended in $25 \mathrm{~mm}$ MES, pH 6.5, $50 \mathrm{~mm} \mathrm{NaCl}, 1 \mathrm{~mm} \mathrm{NaF}, 1 \mathrm{~mm}$
$\mathrm{Na}_{3} \mathrm{VO}_{4}$, and $1 \% \mathrm{TX}-100$ (lysis buffer) supplemented with leupeptin, pepstatin, PMSF, and phosphatase inhibitor cocktails I and II (Calbiochem) and incubated at $0^{\circ} \mathrm{C}$ for $30 \mathrm{~min}$ with Dounce homogenization every $10 \mathrm{~min}$. The cell lysate was then adjusted to $42.5 \%$ sucrose, overlayed with 35 and 5\% sucrose in lysis buffer without TX-100 and sedimented at $275,000 \times g, 4^{\circ} \mathrm{C}$ for $18 \mathrm{hr}$. Fractions were collected from the top of the gradient ( $1 \mathrm{ml}$ fractions in the case of the SW41 rotor, $0.5 \mathrm{ml}$ fractions in the case of the SW55) and stored at $-80^{\circ} \mathrm{C}$ until used. Equal volumes of each fraction were subjected to electrophoresis through Criterion Tris- $\mathrm{HCl}$ polyacrylamide, transferred to PVDF, immunostained with appropriate antibodies, and visualized using West Pico Supersignal (Pierce, Rockford, IL).

To deplete cholesterol, HeLa cells transfected with $\alpha$-synuclein were serum-starved for $2 \mathrm{hr}$ and incubated in $20 \mathrm{~mm} \beta$-methylcyclodextrin for $1 \mathrm{hr}$ at $37^{\circ} \mathrm{C}$ before the isolation of detergent-resistant membranes as above.

Production and analysis of $\alpha$-synuclein transgenic mice. Synuclein cDNAs were subcloned into the cosSHa.Tet cosmid vector (a gift from S. B. Prusiner, University of California San Francisco) downstream of the Syrian hamster prion protein promoter. Transgene constructs were linearized and injected into fertilized ova from outbred mice $(\mathrm{C} 3 \mathrm{H} \times$ C57BL/6J hybrids). Transgenic mice were backcrossed to the C57BL/6] strain, and F5-F10+ generations were used for experiments. Transgene expression in brain was confirmed by Northern and Western analyses. Two transgenic lines, S214 (wild-type) and P263 (A30P mutant), were used for our studies because they had well matched expression levels of $\alpha$-synuclein approximately twofold higher than endogenous.

Isolation of detergent-resistant membranes from brain. Synaptosomes were prepared from mouse cortex as previously described (Hell and Jahn, 1994). Briefly, the cortices of young adult mice were homogenized in 320 mM sucrose and 4 mM HEPES, pH 7.4, containing protease and phosphatase inhibitors (HB). Cell debris was removed by centrifugation at $1350 \times \mathrm{g}$ for $10 \mathrm{~min}$ at $4^{\circ} \mathrm{C}$ and crude synaptosomes sedimented at $12,000 \times g$ for $10 \mathrm{~min}$ at $4^{\circ} \mathrm{C}$. The synaptosomal pellet was washed in $\mathrm{HB}$ and sedimented at $13,000 \times g$ for $15 \mathrm{~min}$. The resulting pellet was resuspended in raft lysis buffer, and detergent-resistant membranes were isolated as described above. Fractions from the flotation gradient were immunoblotted for thy-1 and transferrin receptor as well as human $\alpha$-synuclein, and the synuclein immunoreactivity was quantified by densitometry.

Quantification of fluorescence in hippocampal neurons. Hippocampal neurons were transfected at $7 \mathrm{~d}$ in vitro using Effectene (Qiagen) with pCAGGS-GFP (a gift from J. L. R. Rubenstein, University of California San Francisco), GFP-SV2 (a gift from C. Waites), and GFP- $\alpha$ syn (wildtype and mutants). Neurons were fixed between $17-21 \mathrm{~d}$ in vitro using $4 \%$ PFA and immunostained for synaptophysin, SV2, or dendritic neurofilaments. For cholesterol and sphingolipid depletion, mevalonic acid $(250 \mu \mathrm{M})$, mevastatin $(4 \mu \mathrm{M})$ and fumonisin $\mathrm{B}_{1}(10 \mu \mathrm{M})$ were added on days 12 and 15 in vitro, with fixation and analysis at day 18 . Nystatin (10 $\mu \mathrm{g} / \mathrm{ml}$ ) was added for $20 \mathrm{~min}$ at day 18 in vitro, just before fixation. Confocal images were acquired on a Zeiss LSM 510 microscope with the pinhole opened to $2.5 \mu \mathrm{m}$ for light collection from the whole synapse. Synapses were identified by immunostaining for synaptophysin or SV2. Using the Zeiss LSM510 confocal software, $4 \times 4$ pixel boxes were drawn to cover each synapse, and the fluorescence per pixel for each box was averaged over all the boxes in the field. Axons were identified as weakly fluorescent structures between boutons staining strongly for synaptophysin or SV2, and the fluorescence per pixel from $4 \times 4$ pixel boxes covering the entire length between synapses was averaged over all the axons in the field. The ratio of average fluorescence at synapses divided by average fluorescence at axons was then calculated for individual fields. Multiple fields were then averaged to generate the mean ratios presented in the figures, with the number of fields indicated in the legends.

\section{Results}

To identify the mechanism by which $\alpha$-synuclein localizes to a specific cellular structure such as the nerve terminal, we expressed the protein in HeLa cells using a recombinant adenovirus. $\alpha$-Synuclein tagged at the $\mathrm{C}$ terminus with green fluorescent 

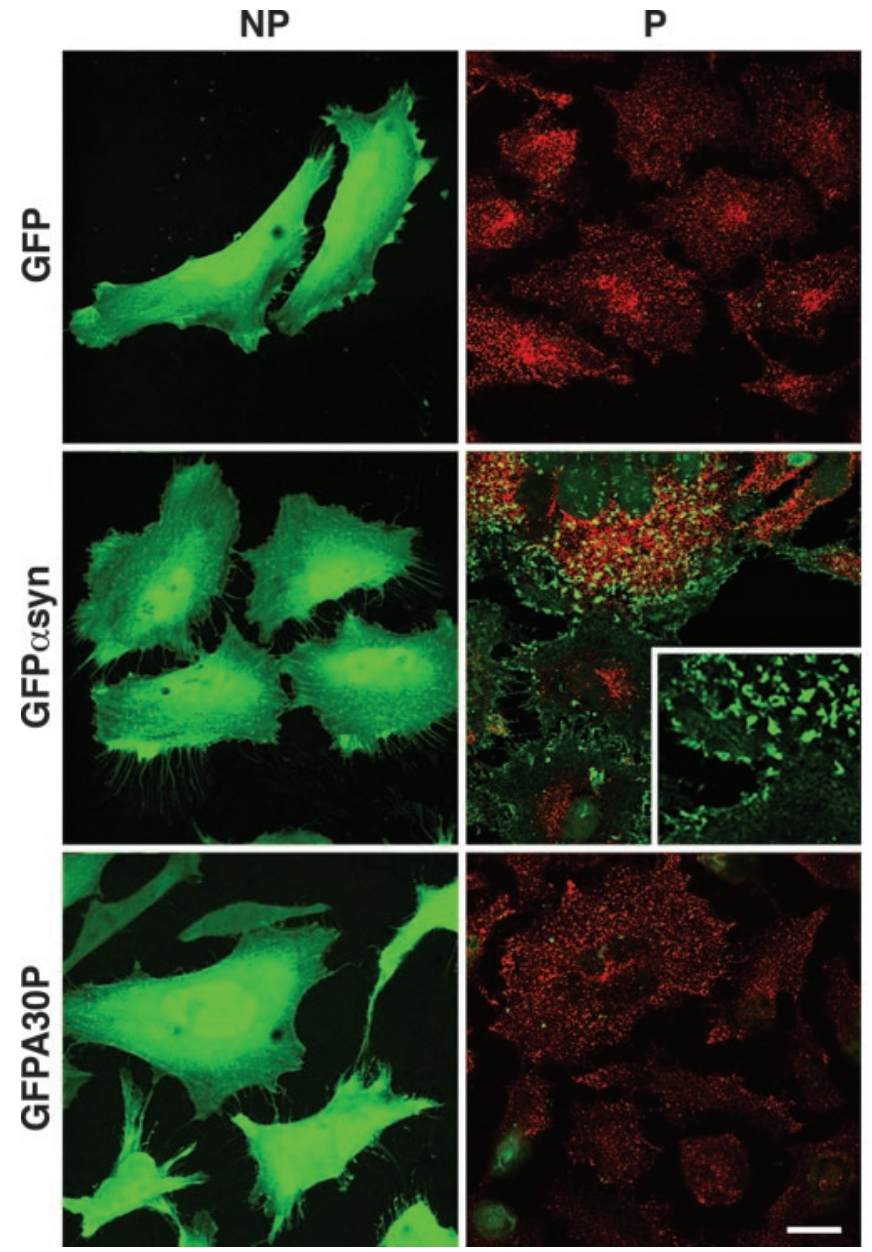

Figure 1. Wild-type but not A30P $\alpha$-synuclein binds specifically to permeabilized HeLa cells. A recombinant adenovirus was used to express GFP, $\alpha$-synuclein-GFP ( $\alpha$ synGFP), and A30P$\alpha$-synuclein-GFP (A30PGFP) in HeLa cells. In intact (NP) cells, $\alpha$ synGFP and A30PGFP have a diffuse cytosolic distribution, similar to GFP. After permeabilization with digitonin for $5 \mathrm{~min}(\mathrm{P})$, the cells specifically retain $\alpha$ synGFP but not GFP. The PD-associated A30P mutation completely abolishes this retention. Permeabilized HeLa cells $(P)$ are double stained for transferrin receptor (red). Scale bar, $20 \mu \mathrm{m}$.

protein ( $\alpha$-synuclein-GFP) and untagged $\alpha$-synuclein (data not shown) exhibit a diffuse distribution that occupies the entire cell volume (Fig. 1), consistent with the behavior of a soluble protein. HeLa cells may lack a structure specific for neurons with which $\alpha$-synuclein normally associates. Alternatively, large amounts of soluble $\alpha$-synuclein may mask a small fraction associated with particular cell structures. To test this possibility, we removed soluble $\alpha$-synuclein by permeabilizing the infected HeLa cells with digitonin before fixation. At the low concentration used (40 $\mu \mathrm{M})$, digitonin selectively permeabilizes the plasma membrane, releasing soluble, cytoplasmic proteins (Schulz, 1990). In HeLa cells expressing $\alpha$-synuclein-GFP, digitonin treatment reveals particulate, residual fluorescence that forms a regular array near the cell surface (Fig. 1). Retained $\alpha$-synuclein also outlines the cell periphery (Fig. 1). The precise pattern of labeling varies from cell to cell, but all permeabilized cells contain residual $\alpha$-synuclein. Similar patterns of labeling were observed for $\alpha$-synuclein tagged at the $\mathrm{N}$ terminus with GFP and untagged $\alpha$-synuclein detected by immunofluorescence (data not shown). Cells expressing GFP show no labeling after permeabilization, indicating the specificity of retention for $\alpha$-synuclein-GFP (Fig. 1). Interestingly, coexpression of untagged wild-type protein reduces retention of wild- type $\alpha$-synuclein-GFP, suggesting that binding is saturable (data not shown). We also observed that $\alpha$-synuclein remains bound to the cells for up to $45 \mathrm{~min}$ after permeabilization (data not shown), indicating a low rate of dissociation in this assay. To assess the potential relevance of this observation for PD, we further examined the retention of A53T and A30P mutants associated with PD. The A53T mutation converts a residue poorly conserved in other species to the normal rodent amino acid, and perhaps consistent with this, has little effect on the retention of human $\alpha$-synuclein by permeabilized HeLa cells (data not shown). In contrast, the A30P mutation affects a highly conserved amino acid and virtually eliminates retention by permeabilized cells (Fig. 1)

To characterize the association of $\alpha$-synuclein with intracellular structures, we added recombinant, bacterially expressed GST- $\alpha$-synuclein to HeLa cells permeabilized with digitonin. Low concentrations of exogenous GST- $\alpha$-synuclein (10 nM) associate with structures very similar to those labeled in infected (or transfected) cells, and the binding appears to saturate $\sim 500 \mathrm{nM}$ (Fig. 2A). Even at high concentrations, recombinant GST shows no binding. In addition, GST-A30P- $\alpha$-synuclein shows no detectable binding at concentrations $<1 \mu \mathrm{M}$ (Fig. 2A), although higher concentrations can weakly label permeabilized HeLa cells in the same general pattern as wild-type $\alpha$-synuclein (data not shown). In contrast, the A53T mutation has no discernible effect on the binding of GST- $\alpha$-synuclein (Fig. $2 A$ ). Taking advantage of the assay with permeabilized cells, we examined the binding of GST- $\alpha$-synuclein (200 nM) in the presence of wild-type or mutant CBP- $\alpha$-synuclein as competitor, detecting the bound GST$\alpha$-synuclein by immunofluorescence for GST. Figure $2 B$ shows that increasing concentrations of wild-type CBP- $\alpha$-synuclein decrease the binding of GST- $\alpha$-synuclein. The same concentrations of CBP-A30P do not inhibit binding of GST- $\alpha$-synuclein (Fig. $2 B)$. By quantitative Western analysis, wild-type and A53T CBP$\alpha$-synuclein reduce the binding of GST- $\alpha$-synuclein with $\mathrm{IC}_{50}$ values $\sim 200 \mathrm{nM}$. In contrast, $5 \mu \mathrm{M}$ CBP-A30P- $\alpha$-synuclein fails to displace the wild-type protein (Fig. 2C).

The pattern of labeling in permeabilized cells indicated that $\alpha$-synuclein localizes to particular cell structures near the plasma membrane. To identify these structures, we double-labeled for several markers of the cytoskeleton and intracellular membranes. Bound GST- $\alpha$-synuclein does not colocalize with filamentous actin or microtubules, nor does it coincide with clathrin-coated pits, endosomes, or focal adhesions (Fig. $3 A$ ). However, bound GST- $\alpha$-synuclein colocalizes extensively with MHC class I (Fig. $3 B$ ), an integral membrane protein suggested to associate with detergent-resistant membrane microdomains known as lipid rafts (Nichols and Lippincott-Schwartz, 2001; Pelkmans et al., 2001). Lipid rafts are thought to be liquid-ordered domains distinct from the liquid-disordered domains that comprise the remainder of cell membranes (Simons and Toomre, 2000). GPIanchored proteins selectively partition into lipid rafts (Brown and Rose, 1992), and bound GST- $\alpha$-synuclein also colocalizes with CD55, a GPI-anchored protein (Fig. 3B). Furthermore, GST- $\alpha$-synuclein labels structures containing $\mathrm{G}_{\mathrm{M} 1}$ (labeled by cholera toxin $\mathrm{B}$ ) and $\mathrm{PIP}_{2}$ (Fig. 3B), lipids enriched in rafts (Pike and Casey, 1996; Brown and London, 1998; Liu et al., 1998). $\alpha$-Synuclein thus colocalizes with components of lipid rafts. In intact cells, rafts are generally considered to be submicroscopic unless specifically clustered by cross-linking (Simons and Toomre, 2000; Sharma et al., 2004). However, depletion of cholesterol in live cells can induce the formation of large, easily detectable membrane microdomains in which different lipid 
probes partition according to their preference for ordered or disordered membrane domains (Hao et al., 2001). Digitonin permeabilizes cells by extracting cholesterol (Schulz, 1990), suggesting that the induced phase separation has enabled us to detect the association of $\alpha$-synuclein with lipid rafts.

Lipid rafts are defined biochemically by their insolubility in Triton X-100 (TX$100)$ at $4^{\circ} \mathrm{C}$ and their behavior as low density membranes during equilibrium sedimentation. We therefore solubilized HeLa cells expressing wild-type $\alpha$-synuclein in TX- 100 at $4^{\circ} \mathrm{C}$, and separated the remaining membranes on a flotation gradient. Under these conditions, a substantial proportion of $\alpha$-synuclein associates with light membranes and cofractionates with the GPI-anchored protein CD55 (Fig. $4 A)$. As expected, transferrin receptor (TfR), which does not associate with lipid rafts, remains at the bottom of the gradient. Perturbing the properties of lipid rafts by depleting cholesterol with $\beta$-methylcyclodextrin dramatically reduces the amount of $\alpha$-synuclein in light fractions (Fig. 5), supporting its association with lipid rafts. Consistent with the results obtained using cells permeabilized with digitonin, the A53T mutation does not significantly affect the partitioning of $\alpha$-synuclein to light membranes (Fig. $4 C)$. In contrast, the A30P mutation primarily eliminates $\alpha$-synuclein binding to lipid rafts (Fig. $4 B$ ). Interestingly, the $\alpha$-synuclein in light membrane fractions migrates more slowly by gel electrophoresis than soluble $\alpha$-synuclein at the bottom of the gradient, suggesting a raftassociated post-translational modification. Previous work has indeed indicated both phosphorylation and O-linked glycosylation of $\alpha$-synuclein (Pronin et al., 2000; Ellis et al., 2001; Nakamura et al., 2001; Shimura et al., 2001), but several phosphatases and O-glycosidase fail to shift the mobility of raft-associated $\alpha$-synuclein back to that of the non-raft protein (data not shown).

To determine whether $\alpha$-synuclein associates with lipid rafts in the brain, we used transgenic mice expressing wild-type and A30P human $\alpha$-synuclein under the control of the prion promoter. These mice produce human $\alpha$-synuclein at levels approximately twofold higher than endogenous $\alpha$-synuclein throughout the brain (M. D. Troyer and R. H. Edwards, unpublished observations), enabling us to examine the behavior of human $\alpha$-synuclein in an experimentally accessible organism. Both wildtype and A30P transgenic mice have no detectable neurological or degenerative phenotype. We prepared synaptosomes from transgenic animals (Hell and Jahn, 1994), solubilized them in TX-100 at $4^{\circ} \mathrm{C}$, and separated the insoluble membranes by flotation on a sucrose density gradient. Using a human-specific antibody for Western blotting, a small proportion of wild-type human $\alpha$-synuclein fractionates with light membranes (Fig. 6A) positive for Thy-1, a GPI-anchored protein, whereas transferrin receptor remains at the bottom of the gradient. The low percentage of raft-associated $\alpha$-synuclein in brain relative to HeLa cells may reflect the high levels of overexpression in the transgenic mice. Alternatively, the interaction between $\alpha$-synuclein and lipid rafts may be disrupted during the time required to prepare synaptosomes, before solubilization in TX-100. Nonetheless, A30P $\alpha$-synuclein shows no second peak of immunoreactivity in light fractions, despite total levels equivalent to that of the transgenic mice overexpressing wild-type protein (Troyer and Edwards, unpublished observations) (Fig. 6B). Quantification of $\alpha$-synuclein immunoreactivity in the light, detergent-resistant membrane fractions of multiple transgenic mice confirms the reduced raft association of $\mathrm{A} 30 \mathrm{P} \alpha$-synuclein (Fig. 6C).

Colocalization with raft components in permeabilized cells and fractionation with detergent-resistant membranes on density gradients suggest that $\alpha$-synuclein associates with rafts under physiological conditions. However, demonstration of the physiological function and indeed the existence of rafts in intact cells have proven elusive (Munro, 2003). To assess the role of raft association in vivo, we have focused on localization of $\alpha$-synuclein to the synapse. The nerve terminal contains choles- 
A

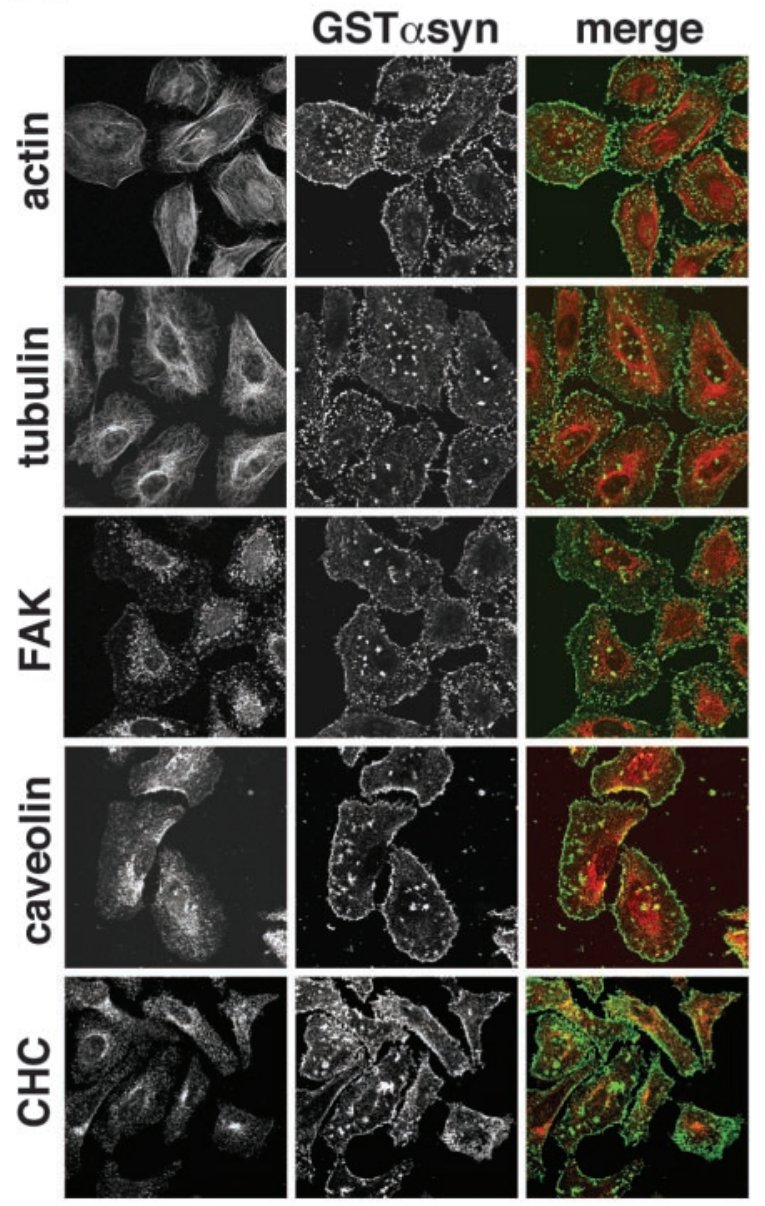

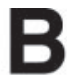

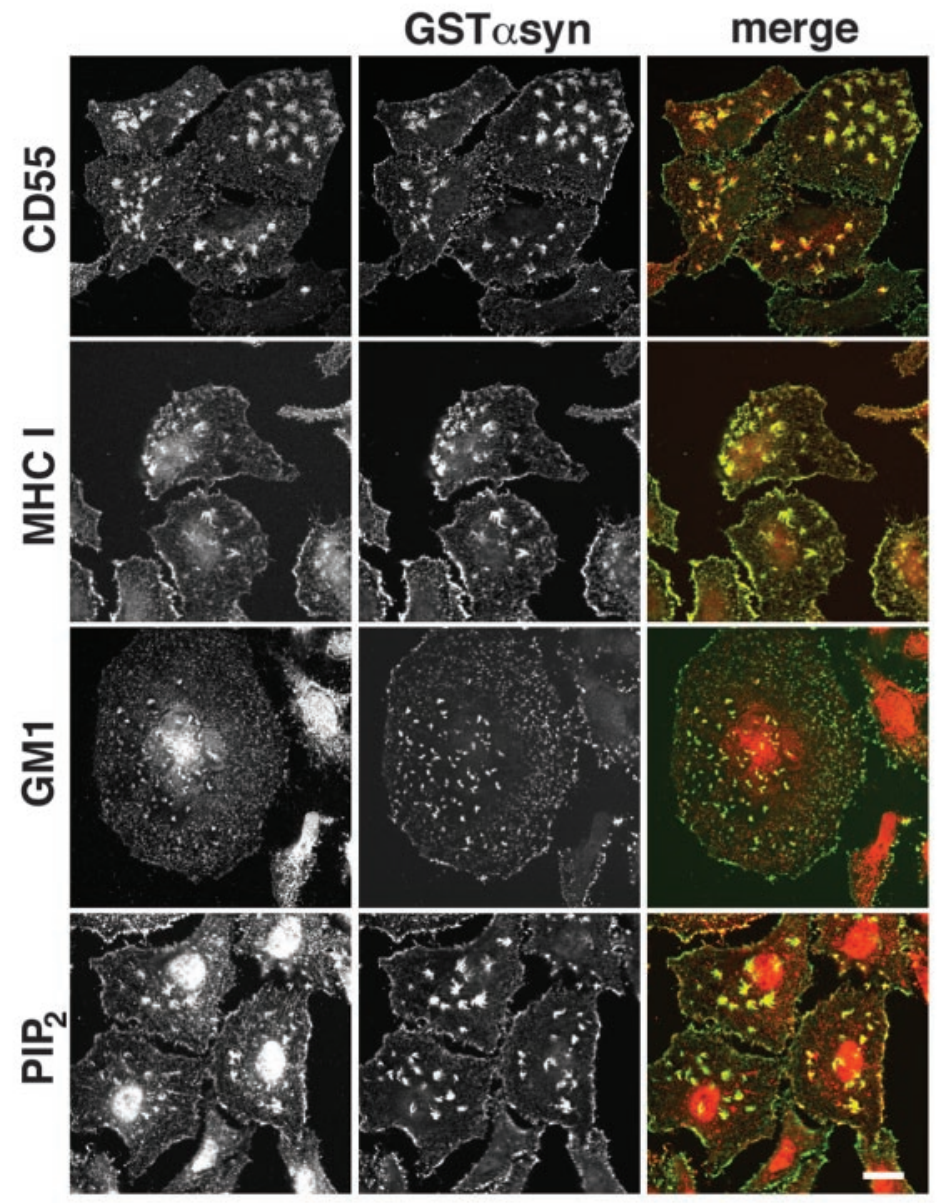

Figure 3. $\alpha$-Synuclein colocalizes with components of lipid rafts in permeabilized HeLa cells. A, HeLa cells were permeabilized in the presence of 200 nm recombinant GST $\alpha$ syn, fixed, immunostained for GST, and double stained for actin, $\alpha$-tubulin, FAK, caveolin-1, and clathrin heavy chain (CHC). Merged images show GST immunoreactivity in green and the different markers in red. Cells immunostained for $\alpha$-tubulin were treated with $10 \mu \mathrm{m}$ Taxol for 30 min before permeabilization to preserve microtubule structure. $\alpha$-Synuclein does not colocalize with any of these markers. $B$, HeLa cells permeabilized in digitonin and $200 \mathrm{nM}$ GST $\alpha$ syn were immunostained for GST and CD55, MHC class I, and PIP 2 . G ${ }_{M 1}$ was detected using cholera toxin subunit B conjugated to biotin followed by streptavidin-Alexa 594. Merged images show GST immunoreactivity in green and the different markers in red. $\alpha$-Synuclein colocalizes extensively with all of these known raft components. Scale bar, $20 \mu \mathrm{m}$.

terol-rich lipid microdomains (Breckenridge et al., 1973; Thiele et al., 2000; Chamberlain et al., 2001; Lang et al., 2001) that might mediate the synaptic localization of $\alpha$-synuclein. Drugs that extract cholesterol from membranes (such as $\beta$-methylcyclodextrin) have been used to disrupt lipid rafts in primary neuronal culture, but also perturb synapse morphology (Hering et al., 2003). We therefore took advantage of the A30P mutation, which specifically disrupts the association of $\alpha$-synuclein with lipid rafts but not with a wide range of artificial membranes (Perrin et al., 2001). We expressed GFP- $\alpha$-synuclein in dissociated hippocampal neurons and compared its synaptic localization to that of GFP as a marker for soluble protein, with GFPA30P- and GFP-A53T- $\alpha$-synuclein and with a GFP fusion to SV2, an integral membrane protein of synaptic vesicles. Using synaptophysin immunofluorescence to identify synapses and the ratio of bouton to axon fluorescence as a quantitative measure of synaptic localization (Sankaranarayanan et al., 2003), GFP- $\alpha$ synuclein (wild-type and A53T) and GFP-SV2 localize preferentially if not exclusively to synaptic varicosities (Fig. 7). As expected for a soluble protein, GFP localizes to axons as well as synaptic boutons and therefore shows much less synaptic enrich- ment (Fig. 7). In contrast to the wild-type protein, GFP-A30P- $\alpha$ synuclein behaves like GFP, localizing to axons as well as boutons. The synaptic enrichment of wild-type and A53T, but not A30P $\alpha$-synuclein, strongly suggests that raft association is required for the synaptic localization of $\alpha$-synuclein.

We assessed directly the role of intact lipid rafts in the localization of $\alpha$-synuclein to the nerve terminal by chronically or acutely disrupting these microdomains in hippocampal neurons.

We first disrupted rafts by blocking the synthesis of cholesterol and sphingolipids with mevalonic acid, mevastatin, and fumonisin $\mathrm{B}_{1}$, a chronic treatment less injurious than acute cholesterol extraction with $\beta$-methylcyclodextrin (Hering et al., 2003). These drugs significantly reduce the proportion of transfected $\alpha$-synuclein at synapses without affecting the synaptic localization of SV2 (Fig. 8). In addition, we treated transfected hippocampal neurons acutely with nystatin, a drug that binds rather than extracts cholesterol and so affects raft structure without the toxicity of $\beta$-methylcyclodextrin (Rothberg et al., 1992). Indeed, nystatin disrupts synaptic morphology less than $\beta$-methylcyclodextrin (data not shown), yet also reduces the synaptic localization of $\alpha$-synuclein (Fig. 8). Pharmacological manipulation in 
A

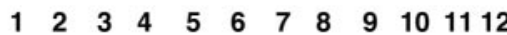

asyn

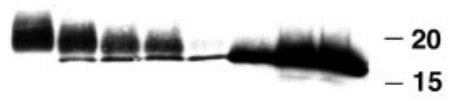

CD55

TfR

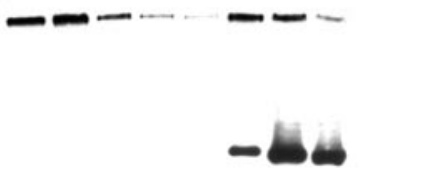

B

A30P

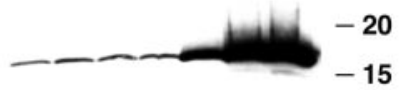

CD55

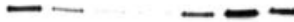

TfR

C

A53T

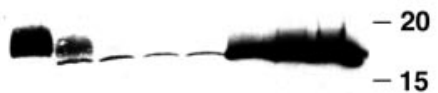

CD55

TfR

Figure 4. $\quad \alpha$-Synuclein fractionates with detergent-resistant membranes. HeLa cells were transfected with wild-type $(A), \mathrm{A30P}(B)$, and A53T ( $C) \alpha$-syn, solubilized in TX-100 at $4^{\circ} \mathrm{C}$ for $30 \mathrm{~min}$, and the extracts were separated by flotation through a sucrose density gradient. Wildtype and A53T $\alpha$-synuclein comigrate with CD55 in light membrane fractions 5-8, whereas the transferrin receptor (TfR) remains at the bottom of the gradient. A30P- $\alpha$-synuclein does not show a peak of immunoreactivity in light fractions. Fractions are numbered from the top of the gradient, and the size markers to the right indicate kilodaltons.

untreated

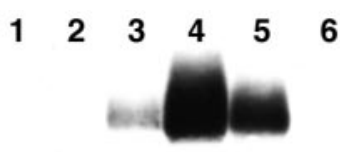

$\beta M C D$

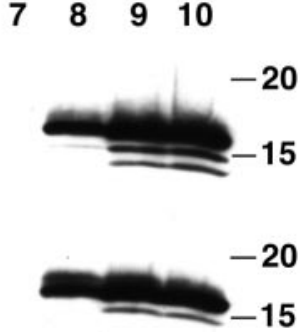

Figure 5. Cholesterol depletion eliminates the association of $\alpha$-synuclein with light membranes. HeLa cells transfected with wild-type $\alpha$-synuclein were treated with $20 \mathrm{~mm}$ $\beta$-methylcyclodextrin ( $\beta$-MCD) for $60 \mathrm{~min}$, solubilized in TX-100, and fractionated as described above. $\beta$-MCD eliminates the $\alpha$-synuclein associated with light membranes observed in untreated cells. Fractions are numbered from the top of the gradient, and the size markers to the right indicate kilodaltons.

neurons thus supports a role for lipid rafts in the synaptic localization of $\alpha$-synuclein.

\section{Discussion}

The results show that $\alpha$-synuclein associates with distinctive structures in HeLa cells that are visualized by the removal of soluble protein through permeabilization with digitonin. We ob-
A

$\begin{array}{llllllllllll}1 & 2 & 3 & 4 & 5 & 6 & 7 & 8 & 9 & 10 & 11 & 12\end{array}$

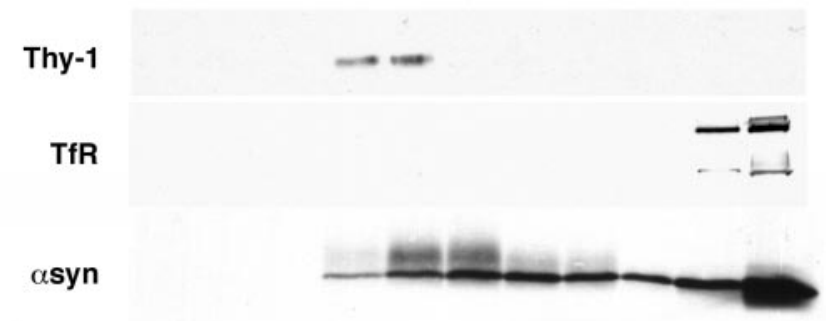

B

Thy-1

TfR

A30P
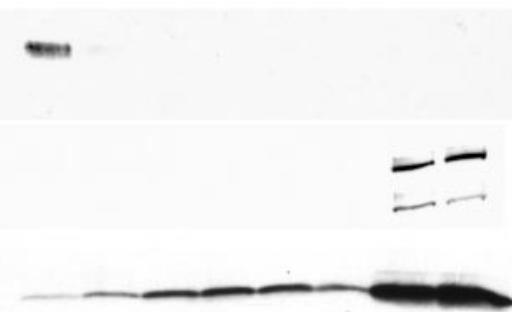

C

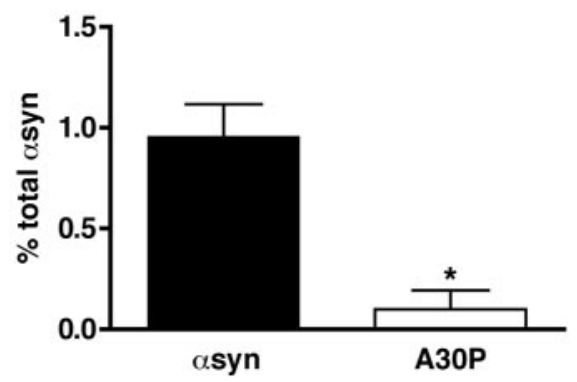

Figure 6. $\alpha$-Synuclein associates with detergent-resistant membranes in mouse brain. Synaptosomes were isolated from the cortices of transgenic mice overexpressing human wild-type (A) and A30P ( $B) \alpha$-synuclein, solubilized in TX-100 and fractionated as described in Figure 3. A proportion of wild-type $\alpha$-synuclein comigrates with Thy-1, whereas transferrin receptor (TfR) remains at the bottom of the gradient. Fractions were collected and numbered from the top of the gradient. $\alpha$-Synuclein immunoreactivity in Thy-1-positive fractions was quantified by densitometry and expressed as a percentage of total immunoreactivity in all fractions. Quantification of the binding from three independent experiments $(C)$ shows a clear reduction in binding for the A30P mutant relative to wild-type $\alpha$-syn. Bar represents averages of three mice \pm SD. ${ }^{*} p=0.0014$; Student's $t$ test.

served this association after both heterologous expression of $\alpha$-synuclein in HeLa cells and the addition of recombinant, bacterially expressed $\alpha$-synuclein to permeabilized HeLa cells that had not been transfected. Both association and competition experiments show that the binding of $\alpha$-synuclein is saturable and high-affinity. In addition, the A30P mutation associated with PD disrupts the association of $\alpha$-synuclein with these structures, supporting the specificity of the interaction. To identify the structures decorated by $\alpha$-synuclein in permeabilized HeLa cells, we used double labeling and found specific colocalization with protein and lipid components of lipid rafts. Although lipid rafts are normally submicroscopic, the digitonin used to permeabilize HeLa cells may have clustered raft components by selectively extracting the cholesterol important for their integrity as a well ordered membrane microdomain (Schulz, 1990; Simons and Toomre, 2000). Indeed, cholesterol depletion induces the clustering of membrane microdomains in live cells (Hao et al., 2001). We therefore confirmed the interaction with rafts using a second, 
A
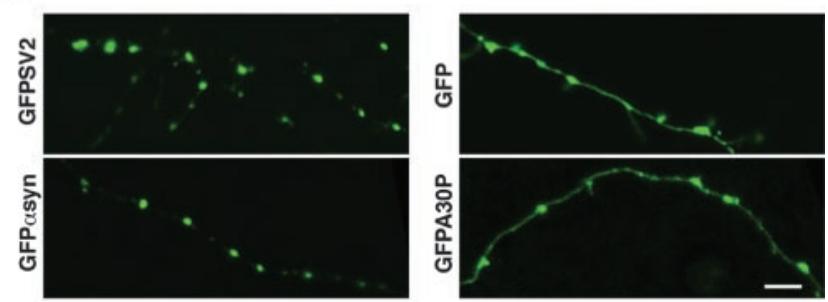

B

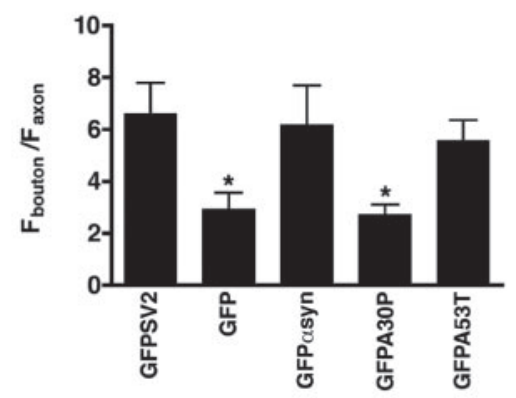

Figure 7. The A30P mutation eliminates synaptic localization of $\alpha$-synuclein. A, Hippocampal neurons transfected with GFPSV2, GFP, GFP $\alpha$ syn, GFPA30P, and GFPA53T were fixed between 17-21 d in vitro, stained, and imaged by confocal microscopy. Scale bar, $5 \mu \mathrm{m}$. $B$, The synaptic enrichment of GFP-tagged protein was determined by calculating the ratio of fluorescence at synapses (identified by synaptophysin staining) to that in neighboring axons. GFP $\alpha$ syn is enriched at synapses to an extent very similar to the GFP fusion with SV2, an integral membrane protein of synaptic vesicles. The PD-associated mutation A30P decreases synaptic enrichment of $\alpha$-synuclein to a level similar to that of GFP alone. For each construct, nine fields from two independent cultures were examined. Bars represent averages \pm SD. ${ }^{*} p<0.0001$ (Student's $t$ test) between GFP $\alpha$ syn and GFP as well as GFP $\alpha$ syn and GFPA30P. The analysis and quantification were performed blind to the plasmid transfected.

biochemical assay. In HeLa cells, $\alpha$-synuclein fractionates with the TX-100-insoluble, light membrane fractions characteristic of lipid rafts. The association of $\alpha$-synuclein with detergentresistant membranes is also sensitive to cholesterol depletion with methyl- $\beta$-cyclodextrin. Furthermore, we have used transgenic mice to show that wild-type human $\alpha$-synuclein also associates with detergent-resistant membranes isolated from brain. In all of these experiments, the $\mathrm{PD}$-associated $\mathrm{A} 30 \mathrm{P}$ mutation primarily eliminates the interaction, whereas the A53T mutation has no detectable effect. Both mutations have not generally affected the interaction of $\alpha$-synuclein with a variety of artificial membranes (Perrin et al., 2000), presumably because these membranes have failed to recapitulate the characteristics of lipid rafts.

Previous studies have shown that $\alpha$-synuclein associates with a number of cell membranes including synaptic vesicles, retrograde axonal transport vesicles, lipid droplets induced by exogenous fatty acid, and yeast plasma membrane (Jensen et al., 1998; Maroteaux et al., 1988; Cole et al., 2002; Outeiro and Lindquist, 2003). Interestingly, the A30P mutation that disrupts the association with lipid rafts has also been found to block the interaction with these membranes. However, the mechanism underlying these interactions has never been delineated. Our results suggest that these interactions also depend on raft-like membrane microdomains. Consistent with this, the lipid droplets with which $\alpha$-synuclein has been shown to associate (Cole et al., 2002) are enriched in cholesterol, very similar to lipid rafts (Brown, 2001). In addition, $\alpha$-synuclein has been reported to bind polyunsaturated fatty acids in vitro (Perrin et al., 2001; Sharon et al., 2001), and polyunsaturated fatty acids have been shown to inhibit signal transduction associated with lipid rafts (Stulnig et al., 1998). The interaction with polyunsaturated fatty acids may therefore regulate the raft association of $\alpha$-synuclein.

Recent work has indicated the presence of membrane microdomains at the nerve terminal. Synaptic vesicles are enriched in cholesterol and contain typical raft components such as GPIanchored proteins. A number of recent reports also implicate raft-like membranes in presynaptic function (Ledesma et al., 1998; Thiele et al., 2000; Chamberlain et al., 2001; Lang et al., 2001). To assess the role of raft association in the synaptic localization of $\alpha$-synuclein, we took advantage of the selective effect of the A30P mutation on raft association and found that the A30P mutation eliminates the localization of $\alpha$-synuclein to the synapse. Chronic treatment with drugs that block the synthesis of cholesterol and sphingolipids, or acute treatment with the cholesterol-binding drug nystatin, both of which disrupt rafts, also reduce the synaptic enrichment of $\alpha$-synuclein. However, it is important to note that lipid rafts occur in the postsynaptic density as well as at the nerve terminal (Hering et al., 2003). Therefore, although required for the synaptic localization of $\alpha$-synuclein, raft association may not be sufficient. Heterogeneity in membrane microdomains may also contribute to the specific presynaptic localization of $\alpha$-synuclein.

The A30P mutation blocks raft association and abolishes the normal synaptic localization of $\alpha$-synuclein. These findings suggest that the A30P mutation contributes to the pathogenesis of familial PD by disrupting the raft association of $\alpha$-synuclein. However, the A53T mutation, which does not interfere with raft binding, also produces the disease. The A53T mutation may have other, uncharacterized effects on the interaction between $\alpha$-synuclein and rafts. Alternatively, the A53T mutation may cause disease through another mechanism. In addition, although most patients with PD lack mutations in $\alpha$-synuclein, our results raise the possibility that changes in the interaction between $\alpha$-synuclein and rafts play an important role in the pathogenesis of idiopathic PD. The extensive dystrophic neurites observed in PD brain label strongly for $\alpha$-synuclein (Galvin et al., 1999), supporting a role for the synaptically localized, raft-associated protein in this form of degeneration. Previous work has shown that lipid binding promotes oligomerization of $\alpha$-synuclein (Perrin et al., 2001; Sharon et al., 2001; Cole et al., 2002) but has inconsistent effects on aggregation in vitro (Lee et al., 2002; Zhu and Fink, 2003). Interestingly, lipid rafts have also been implicated in the pathogenesis of prion disease and Alzheimer's disease (Taraboulos et al., 1995; Ehehalt et al., 2003), neurodegenerative disorders also involving protein aggregation.

Unlike other raft-associated proteins such as amyloid precursor protein and the prion protein, $\alpha$-synuclein lacks a transmembrane domain, lipid anchor, or well defined membrane-binding domain. In vitro, $\alpha$-synuclein forms an amphipathic $\alpha$-helix after binding to artificial membranes (Davidson et al., 1998; Jo et al., 2000; Eliezer et al., 2001; Chandra et al., 2003), but because the A30P mutation either does not affect this interaction or affects it to a much smaller extent than raft association, $\alpha$-synuclein may interact with lipid rafts through a distinct mechanism. In digitonin-permeabilized cells, $\alpha$-synuclein associates with raft components at high affinity. The protein also remains associated with rafts after biochemical fractionation, consistent with a high affinity interaction. In both cases, the clustering of raft components may contribute to the binding affinity. However, we detect only a fraction of $\alpha$-synuclein in detergent-resistant membranes. Biochemical fractionation may therefore also disrupt the normal association of $\alpha$-synuclein with rafts that occurs in intact 
cells. Alternatively, $\alpha$-synuclein may interact in a dynamic way with lipid rafts. In either case, the highly synaptic localization of $\alpha$-synuclein and its dependence on lipid rafts suggest that raft association has an important role in the normal function of $\alpha$-synuclein and its role in PD.

\section{References}

Abeliovich A, Schmitz Y, Farinas I, ChoiLundberg D, Ho WH, Castillo PE, Shinsky N, Verdugo JM, Armanini M, Ryan A, Hynes M, Phillips H, Sulzer D, Rosenthal A (2000) Mice lacking alpha-synuclein display functional deficits in the nigrostriatal dopamine system. Neuron 25:239-252.

Breckenridge WC, Morgan IG, Zanetta JP, Vincendon G (1973) Adult rat brain synaptic vesicles. II. Lipid composition. Biochim Biophys Acta 320:681-686.

Brown DA (2001) Lipid droplets: proteins floating on a pool of fat. Curr Biol 11:R446-449.

Brown DA, London E (1998) Functions of lipid rafts in biological membranes. Annu Rev Cell Dev Biol 14:111-136.

Brown DA, Rose JK (1992) Sorting of GPIanchored proteins to glycolipid-enriched membrane subdomains during transport to the apical cell surface. Cell 68:533-544.

Cabin DE, Shimazu K, Murphy D, Cole NB, Gottschalk W, McIlwain KL, Orrison B, Chen A, Ellis CE, Paylor R, Lu B, Nussbaum RL (2002) Synaptic vesicle depletion correlates with attenuated synaptic responses to prolonged repetitive stimulation in mice lacking alphasynuclein. J Neurosci 22:8797-8807.

Chamberlain LH, Burgoyne RD, Gould GW (2001) SNARE proteins are highly enriched in lipid rafts in PC12 cells: implications for the spatial control of exocytosis. Proc Natl Acad Sci USA 98:5619-5624.

Chandra S, Chen X, Rizo J, Jahn R, Sudhof TC (2003) A broken alpha-helix in folded alpha-synuclein. J Biol Chem 278:15313-15318.

Cole NB, Murphy DD, Grider T, Rueter S, Brasaemle D, Nussbaum RL (2002) Lipid droplet binding and oligomerization properties of the Parkinson's disease protein alpha-synuclein. J Biol Chem 277:6344-6352.

Davidson WS, Jonas A, Clayton DF, George JM (1998) Stabilization of alpha-synuclein secondary structure upon binding to synthetic membranes. J Biol Chem 273:9443-9449.

Ehehalt R, Keller P, Haass C, Thiele C, Simons K (2003) Amyloidogenic processing of the Alzheimer beta-amyloid precursor protein depends on lipid rafts. J Cell Biol 160:113-123.

Eliezer D, Kutluay E, Bussell Jr R, Browne G (2001) Conformational properties of alpha-synuclein in its free and lipid-associated states. J Mol Biol 307:1061-1073.

Ellis CE, Schwartzberg PL, Grider TL, Fink DW, Nussbaum RL (2001) Alpha-synuclein is phosphorylated by members of the Src family of protein-tyrosine kinases. J Biol Chem 276:3879-3884.

Field KA, Holowka D, Baird B (1995) Fc epsilon RI-mediated recruitment of p53/56lyn to detergent-resistant membrane domains accompanies cellular signaling. Proc Natl Acad Sci USA 92:9201-9205.

Galvin JE, Uryu K, Lee VM, Trojanowski JQ (1999) Axon pathology in Parkinson's disease and Lewy body dementia hippocampus contains alpha-, beta-, and gamma-synuclein. Proc Natl Acad Sci USA 96:13450-13455.

George JM, Jin H, Woods WS, Clayton DF (1995) Characterization of a novel protein regulated during the critical period for song learning in the zebra finch. Neuron 15:361-372.

Hao M, Mukherjee S, Maxfield FR (2001) Cholesterol depletion induces large scale domain segregation in living cell membranes. Proc Natl Acad Sci USA 98:13072-13077.

Hardy S, Kitamura M, Harris-Stansil T, Dai Y, Phipps ML (1997) Construction of adenovirus vectors through Cre-lox recombination. J Virol 71:1842-1849.

Hell JW, Jahn R (1994) Preparation of synaptic vesicles from mammalian brain. In: Cell biology, a laboratory handbook (Celis JE, ed). San Diego: Academic.

Hering H, Lin CC, Sheng M (2003) Lipid rafts in the maintenance of synapses, dendritic spines, and surface AMPA receptor stability. J Neurosci 23:3262-3271.

Higgins D, Banker GA (1998) Primary dissociated cell cultures. In: Culturing nerve cells, Ed 2 (Banker GA, Goslin K, eds). Cambridge, MA: MIT.

Iwai A, Masliah E, Yoshimoto M, Ge N, Flanagan L, de Silva HA, Kittel A, Saitoh T (1995) The precursor protein of non-A beta component of Alzheimer's disease amyloid is a presynaptic protein of the central nervous system. Neuron 14:467-475.

Jakes R, Spillantini MG, Goedert M (1994) Identification of two distinct synucleins from human brain. FEBS Lett 345:27-32.

Jensen PH, Nielsen MS, Jakes R, Dotti CG, Goedert M (1998) Binding of alpha-synuclein to brain vesicles is abolished by familial Parkinson's disease mutation. J Biol Chem 273:26292-26294.

Jo E, McLaurin J, Yip CM, St George-Hyslop P, Fraser PE (2000) Alphasynuclein membrane interactions and lipid specificity. J Biol Chem 275:34328-34334.

Jo E, Fuller N, Rand RP, St George-Hyslop P, Fraser PE (2002) Defective membrane interactions of familial Parkinson's disease mutant A30P alpha-synuclein. J Mol Biol 315:799-807.

Kahle PJ, Neumann M, Ozmen L, Muller V, Jacobsen H, Schindzielorz A, Okochi M, Leimer U, van Der Putten H, Probst A, Kremmer E, Kretzschmar HA, Haass C (2000) Subcellular localization of wild-type and Parkinson's disease-associated mutant alpha-synuclein in human and transgenic mouse brain. J Neurosci 20:6365-6373.

Kruger R, Kuhn W, Muller T, Woitalla D, Graeber M, Kosel S, Przuntek H, Epplen JT, Schols L, Riess O (1998) Ala30Pro mutation in the gene encoding alpha-synuclein in Parkinson's disease. Nat Genet 18:106-108.

Lang T, Bruns D, Wenzel D, Riedel D, Holroyd P, Thiele C, Jahn R (2001) SNAREs are concentrated in cholesterol-dependent clusters that define docking and fusion sites for exocytosis. EMBO J 20:2202-2213.

Ledesma MD, Simons K, Dotti CG (1998) Neuronal polarity: essential role of protein-lipid complexes in axonal sorting. Proc Natl Acad Sci USA 95:3966-3971.

Lee HJ, Choi C, Lee SJ (2002) Membrane-bound alpha-synuclein has a high aggregation propensity and the ability to seed the aggregation of the cytosolic form. J Biol Chem 277:671-678.

Liu Y, Casey L, Pike LJ (1998) Compartmentalization of phosphatidylinosi- 
tol 4,5-bisphosphate in low-density membrane domains in the absence of caveolin. Biochem Biophys Res Commun 245:684-690.

Maroteaux L, Campanelli JT, Scheller RH (1988) Synuclein: a neuronspecific protein localized to the nucleus and presynaptic nerve terminal. J Neurosci 8:2804-2815.

Munro S (2003) Lipid rafts: elusive or illusive? Cell 115:377-388.

Murphy DD, Rueter SM, Trojanowski JQ, Lee VM (2000) Synucleins are developmentally expressed, and alpha-synuclein regulates the size of the presynaptic vesicular pool in primary hippocampal neurons. J Neurosci 20:3214-3220.

Nakamura T, Yamashita H, Takahashi T, Nakamura S (2001) Activated Fyn phosphorylates alpha-synuclein at tyrosine residue 125. Biochem Biophys Res Commun 280:1085-1092.

Nichols BJ, Lippincott-Schwartz J (2001) Endocytosis without clathrin coats. Trends Cell Biol 11:406-412.

Outeiro TF, Lindquist S (2003) Yeast cells provide insight into alphasynuclein biology and pathobiology. Science 302:1772-1775.

Pelkmans L, Kartenbeck J, Helenius A (2001) Caveolar endocytosis of simian virus 40 reveals a new two-step vesicular-transport pathway to the ER. Nat Cell Biol 3:473-483.

Perrin RJ, Woods WS, Clayton DF, George JM (2000) Interaction of human alpha-synuclein and Parkinson's disease variants with phospholipids. Structural analysis using site-directed mutagenesis. J Biol Chem 275:34393-34398.

Perrin RJ, Woods WS, Clayton DF, George JM (2001) Exposure to long chain polyunsaturated fatty acids triggers rapid multimerization of synucleins. J Biol Chem 276:41958-41962.

Pike LJ, Casey L (1996) Localization and turnover of phosphatidylinositol 4,5-bisphosphate in caveolin-enriched membrane domains. J Biol Chem 271:26453-26456.

Polymeropoulos MH, Lavedan C, Leroy E, Ide SE, Dehejia A, Dutra A, Pike B, Root H, Rubenstein J, Boyer R, Stenroos ES, Chandrasekharappa S, Athanassiadou A, Papapetropoulos T, Johnson WG, Lazzarini AM, Duvoisin RC, Di Iorio G, Golbe LI, Nussbaum RL (1997) Mutation in the alphasynuclein gene identified in families with Parkinson's disease. Science 276:2045-2047.

Pronin AN, Morris AJ, Surguchov A, Benovic JL (2000) Synucleins are a novel class of substrates for $\mathrm{G}$ protein-coupled receptor kinases. J Biol Chem 275:26515-26522.

Rothberg KG, Heuser JE, Donzell WC, Ying YS, Glenney JR, Anderson RG (1992) Caveolin, a protein component of caveolae membrane coats. Cell 68:673-682.

Sankaranarayanan S, Atluri PP, Ryan TA (2003) Actin has a molecular scaffolding, not propulsive, role in presynaptic function. Nat Neurosci 6:127-135.

Schulz I (1990) Permeabilizing cells: some methods and applications for the study of intracellular processes. Methods Enzymol 192:281-300.

Sharma P, Varma R, Sarasij RC, Ira, Gousset K, Krishnamoorthy G, Rao M,
Mayor S (2004) Nanoscale organization of multiple GPI-anchored proteins in living cell membranes. Cell 116:577-589.

Sharon R, Goldberg MS, Bar-Josef I, Betensky RA, Shen J, Selkoe DJ (2001) alpha-Synuclein occurs in lipid-rich high molecular weight complexes, binds fatty acids, and shows homology to the fatty acid-binding proteins. Proc Natl Acad Sci USA 98:9110-9115.

Shimura H, Schlossmacher MG, Hattori N, Frosch MP, Trockenbacher A, Schneider R, Mizuno Y, Kosik KS, Selkoe DJ (2001) Ubiquitination of a new form of alpha-synuclein by parkin from human brain: implications for Parkinson's disease. Science 293:263-269.

Simons K, Toomre D (2000) Lipid rafts and signal transduction. Nat Rev Mol Cell Biol 1:31-39.

Singleton AB, Farrer M, Johnson J, Singleton A, Hague S, Kachergus J, Hulihan M, Peuralinna T, Dutra A, Nussbaum R, Lincoln S, Crawley A, Hanson M, Maraganore D, Adler C, Cookson MR, Muenter M, Baptista M, Miller D, Blancato J, Hardy J, Gwinn-Hardy K (2003) Alpha-synuclein locus triplication causes Parkinson's disease. Science 302:841.

Spillantini MG, Schmidt ML, Lee VM, Trojanowski JQ, Jakes R, Goedert M (1997) Alpha-synuclein in Lewy bodies. Nature 388:839-840.

Spillantini MG, Crowther RA, Jakes R, Hasegawa M, Goedert M (1998) Alpha-synuclein in filamentous inclusions of Lewy bodies from Parkinson's disease and dementia with Lewy bodies. Proc Natl Acad Sci USA 95:6469-6473.

Stulnig TM, Berger M, Sigmund T, Raederstorff D, Stockinger H, Waldhausl W (1998) Polyunsaturated fatty acids inhibit T cell signal transduction by modification of detergent-insoluble membrane domains. J Cell Biol 143:637-644.

Taraboulos A, Scott M, Semenov A, Avrahami D, Laszlo L, Prusiner SB, Avraham D (1995) Cholesterol depletion and modification of COOHterminal targeting sequence of the prion protein inhibit formation of the scrapie isoform. J Cell Biol 129:121-132.

Thiele C, Hannah MJ, Fahrenholz F, Huttner WB (2000) Cholesterol binds to synaptophysin and is required for biogenesis of synaptic vesicles. Nat Cell Biol 2:42-49.

Ueda K, Fukushima H, Masliah E, Xia Y, Iwai A, Yoshimoto M, Otero DA, Kondo J, Ihara Y, Saitoh T (1993) Molecular cloning of cDNA encoding an unrecognized component of amyloid in Alzheimer disease. Proc Natl Acad Sci USA 90:11282-11286.

Withers GS, George JM, Banker GA, Clayton DF (1997) Delayed localization of synelfin (synuclein, NACP) to presynaptic terminals in cultured rat hippocampal neurons. Dev Brain Res 99:87-94.

Zarranz JJ, Alegre J, Gomez-Esteban JC, Lezcano E, Ros R, Ampuero I, Vidal L, Hoenicka J, Rodriguez O, Atares B, Llorens V, Gomez Tortosa E, del Ser T, Munoz DG, de Yebenes JG (2004) The new mutation, E46K, of alphasynuclein causes Parkinson and Lewy body dementia. Ann Neurol 55:164-173.

Zhu M, Fink AL (2003) Lipid binding inhibits alpha-synuclein fibril formation. J Biol Chem 278:16873-16877. 